\title{
Dukes's classification: a valid prognostic indicator for gastric cancer
}

\author{
Y Adachi, M Mori, Y Maehara, K Sugimachi
}

\begin{abstract}
Dukes's classification for colorectal cancer is simple, and correlates well with survival. This study assessed whether the principles of Dukes's classification applied to gastric cancer resulted in the separation of prognostically useful groups. The cumulative survival curves determined by Dukes's, Astler-Coller's (another classification for colorectal cancer), and the Japanese classification for gastric cancer were evaluated using 476 curatively treated patients with gastric cancer. Of the three staging systems, both Dukes's and the Japanese classifications showed a step-wise relationship between the stage of the tumour and the survival of patients. The prognostic value of Dukes's classification was reinforced when Dukes's C cases were subdivided according to the number of positive nodes $(1-6 v \geqslant 7)$ or the level of positive nodes (n1 $v$ n2, n3) but not when the subdivision was made according to the depth of wall invasion. A modified Dukes's classification in which Dukes's cases are subdivided according to the number of metastatic nodes (Dukes's $\mathrm{Ca}=1-6$ nodes, Dukes's $\mathrm{Cb}>6$ nodes) could be both simply and accurately applied to gastric cancer. (Gut 1994; 35: 1368-1371)
\end{abstract}

Pathological staging of tumours is important and is widely used to determine optimal treatment, assess prognosis, and evaluate treatment results. ${ }^{1}$ For gastric cancer in Japan, the Japanese staging system outlined by the Japanese Research Society for Gastric Cancer ${ }^{2}$ is generally used ${ }^{3}$ but this is not so well known in western countries.

Dukes's classification ${ }^{4}$ for colorectal cancer is simple, easy to recall, and correlates well with survival, and most gastroenterologists all over the world use it as an important prognostic indicator. ${ }^{5}$ Astler-Coller's classification ${ }^{6}$ also gives useful prognostic information in colorectal cancer.

In order to clarify whether or not Dukes's and Astler-Coller's classifications are also useful in gastric cancer, we analysed 476 curatively treated patients with gastric cancer and tested the criteria of Dukes's, Astler-Collier's, and the Japanese classifications. In addition, we sought a better staging system by modifying Dukes's classification.

\section{Patients and methods}

A consecutive series of 476 cases of gastric cancer was studied. All patients were curatively treated by either partial or total gastrectomy with lymph node dissection, and all resected specimens were examined histologically (using haematoxylin and eosin stains) in the Second Department of Surgery, Kyushu University between January 1975 and February 1986. No patient had liver or lung metastasis, peritoneal dissemination, extended lymph node metastasis, or adjacent organ involvement. In this series, lung and liver metastases were excluded by chest $x$ ray, ultrasonography, and computed tomography, and extended lymph node metastasis was defined as involvement of the lymph nodes along the superior mesenteric artery, middle colic artery and abdominal aorta, and Virchow's node. Any cancers of the remnant stomach or cancers other than adenocarcinoma were excluded.

The stage of the disease was determined by the histological findings using the criteria of Dukes's, Astler-Coller's, and the Japanese staging systems. In Dukes's classification, ${ }^{4}$ ' $A$ ' included tumours limited to the mucosa, submucosa, or muscularis propria; ' $B$ ' included those extending into the subserosa or serosa; and ' $\mathrm{C}$ ' included those with lymph node metastasis. In Astler-Coller's classification, ${ }^{6}$ ' $\mathrm{A}$ ' included tumours limited to the mucosa; ' $\mathrm{B} 1$ ' included those invading the submucosa or muscularis propria; 'B2' included those extending into the subserosa or serosa; ' $\mathrm{C} 1$ ' included those not invading beyond the muscularis propria with lymph node metastasis; and ' $\mathrm{C} 2$ ' included those extending beyond the muscularis propria with lymph node metastasis. In the Japanese classification, ${ }^{2}$ ' $I$ ' included tumours not invading beyond the subserosa without lymph node metastasis; 'II' included those extending into the subserosa or with positive group 1 nodes (n1); 'III' included those affecting the serosa or with positive group 2 nodes (n2); and 'IV' included those with positive group 3 nodes (n3).

The clinicopathological findings, including the level of lymph node metastasis, were analysed according to the general rules for gastric cancer study in surgery and pathology outlined by the Japanese Research Society for Gastric Cancer. ${ }^{2}$ Follow up continued until death, or for more than five years for surviving patients. Information was obtained from death certificates. When death from recurrent gastric cancer was specified, the patient was included as a tumour-related death. The cumulative survival rates were calculated using the Kaplan-Meier method, and survival curves were tested using the Mantel-Cox method.

Second Department of
Surgery, Faculty of
Medicine, Kyushu
University, Fukuoka,
Japan
Y Adachi
M Mori
Y Maehara
K Sugimachi
Correspondence to:
Dr Y Adachi, Second
Department of Surgery,
Faculty of Medicine, Kyushu
University, 3-1-1 Maidashi,
Higashi-ku, Fukuoka 812,
Japan.
Accepted for publication
31 January 1994

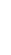



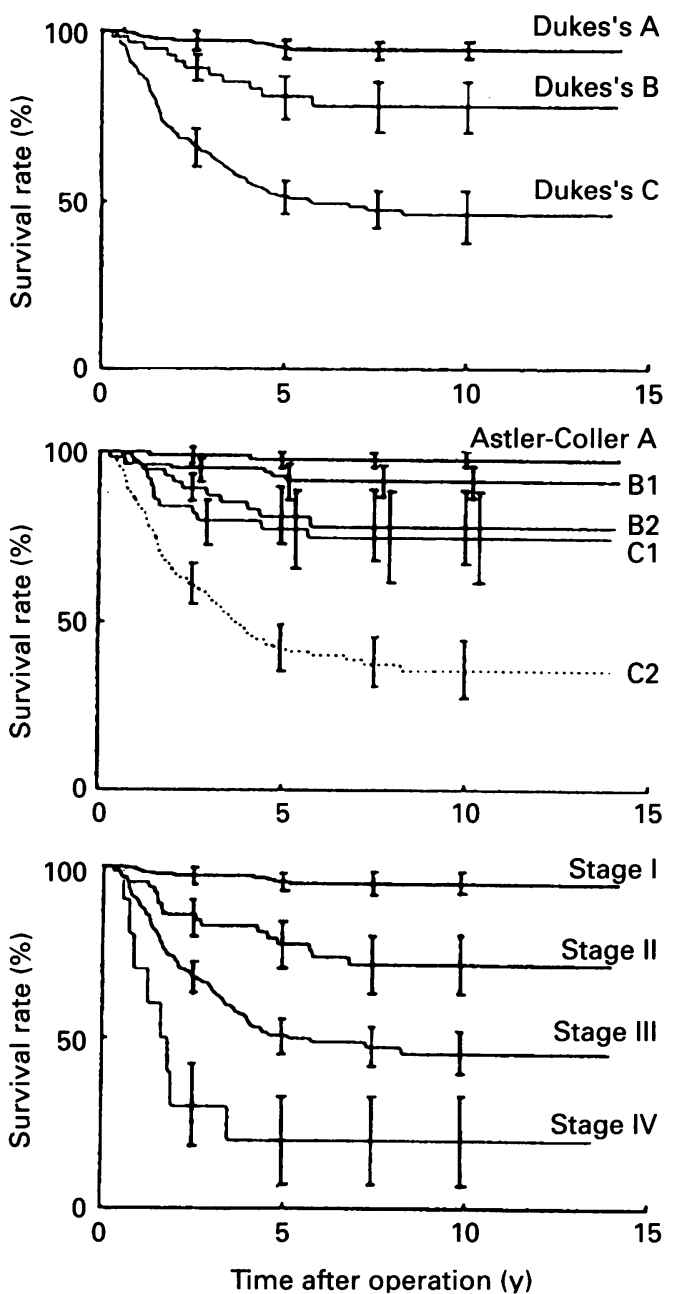

Figure 1: Cumulative survival curves for 476 patients with curatively treated gastric cancer according to the criteria of Dukes's (top), Astler-Coller's (middle), and Fapanese (bottom) classifications. Vertical bars represent $95 \%$ confidence intervals.

\section{Results}

DUKES'S AND OTHER CLASSIFICATIONS

According to the criteria of Dukes's, AstlerColler's, and the Japanese staging systems, cumulative survival curves and five and 10 year survival rates were calculated (Fig 1, Table I). Dukes's classification showed a clear correlation between tumour stage and survival. The five and 10 year survival rates were excellent in Dukes's A cases (95\%, 95\%), good in Dukes's B $(81 \%, 78 \%)$, and fair in Dukes's C $(52 \%$, $46 \%$ ). Astler-Coller's classification also showed a correlation between tumour stage and survival, but there was no step-wise relationship between stage and survival. The five and 10 year survival rates were similar in $\mathrm{A}$ cases $(98 \%, 98 \%)$ and $\mathrm{B} 1$ cases $(93 \%, 92 \%)$, and between $\mathrm{B} 2$ cases $(81 \%, 78 \%)$ and $\mathrm{C} 1$ cases $(78 \%, 75 \%)$. In the Japanese staging system, there was good correlation between tumour stage and survival. The five and 10 year survival rates were excellent in stage I cases $(96 \%, 95 \%)$, good in stage II $(77 \%$, $71 \%)$, fair in stage III $(51 \%, 45 \%)$, and bad in stage IV $(20 \%, 20 \%)$, although the distribution of the number of patients in each stage was uneven (stage IV, for example, included only $2 \%$ of patients).
TABLE I Five and 10 year survival rates in gastric cancer based on the Dukes's, Astler-Coller, and Fapanese classifications

\begin{tabular}{llll}
\hline Staging system & $\begin{array}{l}\text { No of } \\
\text { patients }\end{array}$ & $\begin{array}{l}5 \text { year } \\
\text { survival rate } \\
(\%)\end{array}$ & $\begin{array}{l}\text { 10 year } \\
\text { survival rate } \\
(\%)\end{array}$ \\
\hline Dukes's: & & & \\
A & 220 & 95 & 95 \\
B & 61 & 81 & 78 \\
C & 195 & 52 & 46 \\
Astler-Coller's: & 112 & 98 & 98 \\
A & 108 & 93 & 92 \\
B1 & 61 & 81 & 78 \\
B2 & 52 & 78 & 75 \\
C1 & 143 & 42 & 36 \\
C2 & 233 & 96 & 95 \\
Japanese stage: & 66 & 77 & 71 \\
I & 167 & 51 & 45 \\
II & 10 & 20 & 20 \\
III & & & \\
IV & & & \\
\hline
\end{tabular}

SUBDIVISION OF DUKES'S C CASES

Since Dukes's C cases consisted of many and various patients with node-positive gastric cancer, we tried to divide Dukes's C cases into two subgroups according to the depth of wall invasion, the number of positive nodes, and the level of positive nodes (Fig 2, Table II). Firstly, Dukes's C cases were subdivided according to the depth of wall invasion: $\mathrm{Ca}$ cases in which tumour invasion was not beyond the muscularis propria (52 cases); and $\mathrm{Cb}$ cases in which tumour invasion was beyond the muscularis propria (143 cases). The five and 10 year survival rates of $\mathrm{Ca}$ cases $(78 \%$, $75 \%$ ) were obviously different from those of $\mathrm{Cb}$ cases $(42 \%, 36 \%)$, but were almost the same as those of $B$ cases $(81 \%, 78 \%)$. Secondly, Dukes's C cases were subdivided according to the number of positive nodes: $\mathrm{Ca}$ cases had 1-6 positive nodes (134 cases) and $\mathrm{Cb}$ cases $\geqslant 7$ positive nodes (61 cases). The five and 10 year survival rates of the former $(64 \%, 59 \%)$ and the latter $(25 \%, 18 \%)$ were clearly different from each other and from those of B cases $(81 \%, 78 \%)$. Lastly, Dukes's $\mathrm{C}$ cases were subdivided according to the level of the positive nodes: $\mathrm{Ca}$ cases ( $\mathrm{n} 1$ ) in which group 1 nodes were positive (116 cases); and $\mathrm{Cb}$ cases $(\mathrm{n} 2, \mathrm{n} 3)$ in which group 2 or 3 nodes were positive ( 79 cases). The five and 10 year survival rates of the former $(66 \%, 62 \%)$ and the latter $(32 \%, 24 \%)$ were also different from each other and from those of B cases $(81 \%$, $78 \%$ ). Thus the prognostic value of Dukes's classification was reinforced when Dukes's C cases were subdivided according to the number or level of positive nodes.

\section{Discussion}

In 1932 , Dukes ${ }^{4}$ proposed a staging system for rectal cancer based on the degree of tumour invasion and either the presence or absence of lymph node metastasis. In 1935, Gabriel, Dukes, and Bussey ${ }^{7}$ subdivided $\mathrm{C}$ cases into C1 cases in which only regional lymph nodes contained metastases and $\mathrm{C} 2$ cases in which apical mesenteric nodes were affected. The classification was simple and accurate, and was soon applied to colonic cancer. In 1954, Astler and Coller ${ }^{6}$ advocated another useful staging system for colorectal cancer. C cases, with 

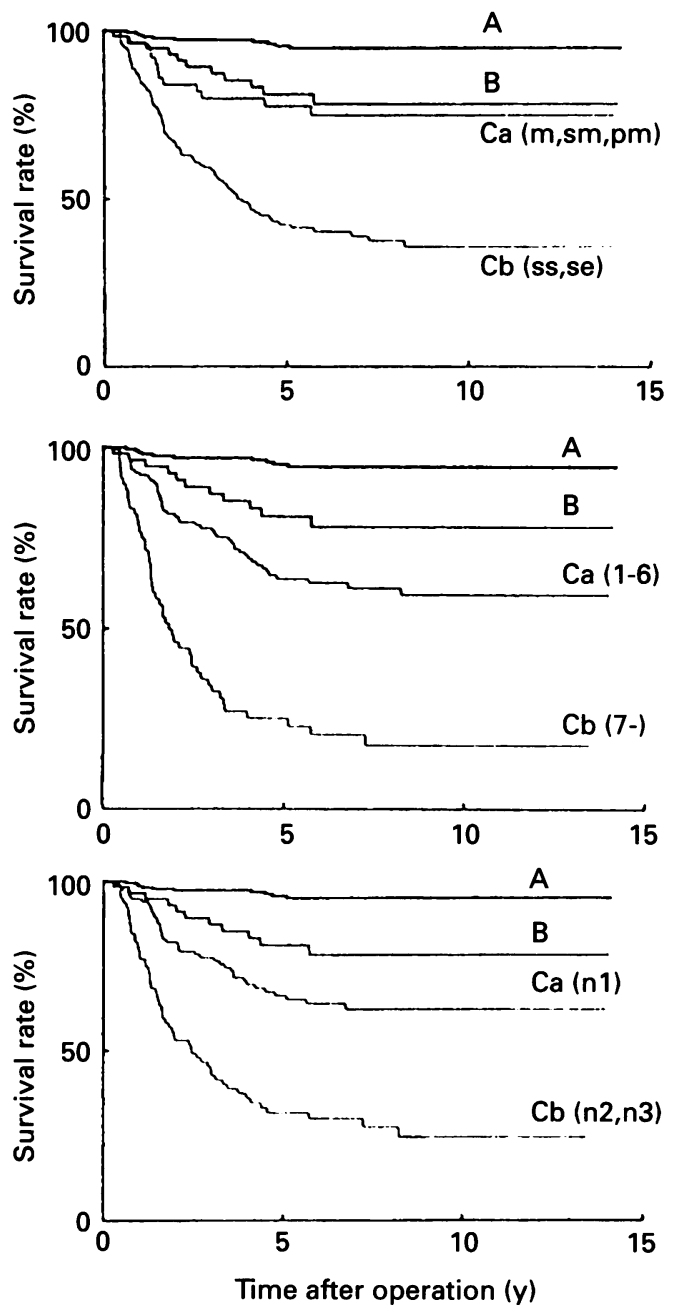

Figure 2: Cumulative survival curves for 476 patients with curatively treated gastric cancer according to the criteria of Dukes's classification with Dukes's C cases subdivided according to depth of wall invasion (top), number of positive nodes (middle), and level of positive nodes (bottom).

lymph node metastasis, were subdivided into $\mathrm{C} 1$ cases in which the tumour was confined within the wall and $\mathrm{C} 2$ cases in which the tumour penetrated through the wall. Various other staging systems for colorectal cancer have been described by many authors, but the Dukes's and Astler-Coller's classifications have been the most widely used since they are simple, easy to remember, and accurate in estimating prognosis. ${ }^{5}$

With regard to the staging system for gastric cancer, a TNM classification by the American Joint Committee on Cancer $^{8}$ is popular in western countries, while a Japanese classification by the Japanese Research Society for Gastric Cancer $^{2}$ is preferred in Japan. Recently, it was suggested that the TNM classification reflected treatment results more accurately than the Japanese classification. ${ }^{9}$ The TNM classification is difficult to memorise, however, since there are six stages consisting of 13 categories. The Japanese classification is also complex in numbering and grouping of lymph nodes. In order to evaluate the surgical results of gastric cancer in various countries and hospitals, a simple and easy staging system, such as Dukes's classification, is therefore needed.
TABLE II Five and 10 year survival rates in gastric cancer after modification of Dukes's $C$ cases

\begin{tabular}{lcll}
\hline & $\begin{array}{l}\text { No of } \\
\text { patients }\end{array}$ & $\begin{array}{l}5 \text { year } \\
\text { survival rate } \\
(\%)\end{array}$ & $\begin{array}{l}10 \text { year } \\
\text { survival rate } \\
(\%)\end{array}$ \\
Staging system & & & \\
\hline Dukes's depth of invasion & 220 & 95 & 95 \\
A & 61 & 81 & 78 \\
B & 52 & 78 & 75 \\
Ca (m, sm, pm) & 143 & 42 & 36 \\
Cb (ss, se) & 220 & 95 & 95 \\
Dukes's number of nodes involved & & 78 \\
A & 61 & 81 & 59 \\
B & 134 & 64 & 18 \\
Ca (1-6) & 61 & 25 & 95 \\
Cb (7-) & 220 & 95 & 78 \\
Dukes's level of nodes involved & & 62 \\
B & 61 & 81 & 24 \\
Ca (n1) & 116 & 66 & \\
Cb (n2, n3) & 79 & 32 & \\
\hline
\end{tabular}

$\mathrm{m}=$ mucosa; $\mathrm{sm}=$ submucosa; $\mathrm{pm}=$ muscularis propria; $\mathrm{ss}=$ subserosa; $\mathrm{se}=$ serosa; $\mathrm{n} \mathbf{1}=$ positive group 1 nodes; $\mathrm{n} 2$ $\mathrm{n} 3=$ positive group 2,3 nodes

Under these circumstances, we have tried to apply the Dukes's and Astler-Coller's classifications to gastric cancer, and tested whether or not these staging systems for colorectal cancer are valuable in gastric cancer. When prognostic value was compared in Dukes's, AstlerColler's, and the Japanese staging systems, the Dukes's and the Japanese classifications clearly showed a close correlation between the stage of tumours and patient survival. Astler-Coller's classification was inferior to the others since separation between the stages was much less clear cut. Therefore, it was considered that Dukes's classification could also be successfully applied to gastric cancer as a simple and useful staging system.

In our study, the subdivision of Dukes's C cases was assessed in order to reinforce its prognostic importance. Subdivision according to the depth of wall invasion was inadequate, because the survival rate was similar for B cases (deeply invasive without nodal metastasis) and $\mathrm{Ca}$ cases (superficially invasive with nodal metastasis). On the contrary, subdivision according to the number and level of metastatic nodes was very significant. With regard to the number of positive nodes, its prognostic significance has been shown in cancers of the breast, ${ }^{10}$ colorectum, ${ }^{5}$ and stomach. ${ }^{11-14} \mathrm{We}$ recently clarified that survival of patients with node-positive gastric cancer was independently influenced by the number of positive nodes, survival rates markedly decreasing when the number of metastatic nodes exceeded six. ${ }^{15}$ Therefore, it is suggested that a modified Dukes's classification according to the number of positive nodes would provide more essential information in patients with gastric cancer.

In conclusion, the results indicate that Dukes's classification can be well applied to gastric cancer as a simple and useful staging system, and a modified Dukes's classification according to the number or level of positive nodes provides further important prognostic information. Application of Dukes's classification will contribute to the further pathological assessment of gastric cancer.

1 Carr DT. Is staging of cancer of value? Cancer 1983; 51: 2503-5. 
2 Japanese Research Society for Gastric Cancer. The general rules for the gastric cancer study in surgery and pathology. rules for the gastric cancer study

3 Maehara Y, Okuyama T, Moriguchi S, Orita H, Kusumoto H, Korenaga D, Sugimachi K. Prophylactic lymph node dissection in patients with advanced gastric cancer promotes increased survival time. Cancer 1992; 70: 392-5.

4 Dukes CE. The classification of cancer of the rectum. Pathol 1932; 35: 323-32.

5 Fisher ER, Sass R, Palekar A, Fisher B, Wolmark N. Dukes's classification revisited: Findings from the National Surgical Adjuvant Breast and Bowel Projects (Protocol R-01). Cancer 1989; 64: 2354-60.

6 Astler VB, Coller FA. The prognostic significance of direct extension of carcinoma of the colon and rectum. Ann Surg

7 Gabriel WB, Dukes CE, Bussey HJ. Lymphatic spread in cancer of the rectum. Br f Surg 1935; 23: 395-413.

8 American Joint Committee on Cancer. Stomach cancer. In: Manual for staging cancer. Philadelphia: JB Lippincott Co, 1983; 67-72.

9 Nio Y, Tsubono M, Kawabata K, Masai Y, Hayashi $H$, Meyer C, et al. Comparison of survival curves of gastric cancer patients after surgery according to the UICC stage classification and the general rules for gastric cancer study by the Japanese Research Society for Gastric Cancer. Ann Surg 1993; 218: 47-53.
10 Barth RJ Jr, Danforth DN Jr, Venzon DJ, Straus KL, d'Angelo T, Merino MJ, et al. Level of axillary involvement by lymph node metastases from breast cancer is not an independent predictor of survival. Arch Surg 1991; 126: $574-7$.

11 Jaehne J, Meyer HJ, Maschek H, Geerlings H, Bruns E, Pichlmayr R. Lymphadenectomy in gastric carcinoma: A prospective and prognostic study. Arch Surg 1992; 127: 290-4.

12 Makino M, Moriwaki S, Yonekawa M, Oota M, Kimura O, Kaibara N. Prognostic significance of the number of metastatic lymph nodes in patients with gastric cancer. f Surg Oncol 1991; 47: 12-6.

13 Okusa T, Nakane Y, Boku T, Takada H, Yamamura M, Hioki $\mathrm{K}$, Yamamoto $\mathrm{M}$. Quantitative analysis of modal involvement with respect to survival after curative gastrectomy for carcinoma. Surg Gynecol Obstet 1990; 170: 488-94.

14 Shiu MH, Perrotti M, Brennan MF. Adenocarcinoma of the stomach: a multivariate analysis of clinical, pathologic and treatment factors. Hepato-Gastroenterol 1989; 36: 7-12.

15 Adachi Y, Kamakura T, Mori M, Baba H, Maehara Y, Sugimachi K. Prognostic significance of the number of positive lymph nodes in gastric carcinoma. $\mathrm{Br} \mathcal{F}$ Surg $1994 ; 81: 414-6$. 